\title{
Nathalie Solomon, Voyages et fantasmes de voyages à l'époque romantique
}

\author{
Michel Arrous
}

\section{(2) OpenEdition}

1 Journals

\section{Édition électronique}

URL : http://journals.openedition.org/studifrancesi/1361

DOI : 10.4000/studifrancesi. 1361

ISSN : 2421-5856

Éditeur

Rosenberg \& Sellier

\section{Édition imprimée}

Date de publication : 1 décembre 2015

Pagination : 597-598

ISSN : 0039-2944

\section{Référence électronique}

Michel Arrous, « Nathalie Solomon, Voyages et fantasmes de voyages à l'époque romantique », Studi

Francesi [En ligne], 177 (LIX | III) | 2015, mis en ligne le 01 décembre 2015, consulté le 06 janvier 2021 URL : http://journals.openedition.org/studifrancesi/1361; DOI : https://doi.org/10.4000/studifrancesi. 1361

Ce document a été généré automatiquement le 6 janvier 2021.

\section{(c) $($ ) $\odot$ EY}

Studi Francesi è distribuita con Licenza Creative Commons Attribuzione - Non commerciale - Non opere derivate 4.0 Internazionale. 


\title{
Nathalie Solomon, Voyages et fantasmes de voyages à l'époque romantique
}

\author{
Michel Arrous
}

\section{RÉFÉRENCE}

NATHALIE SOLOMON, Voyages et fantasmes de voyages à l'époque romantique, Toulouse, Presses universitaires du Mirail, 2014, pp. 307.

1 À en croire Roger de Beauvoir, il y aurait le «touriste littéraire» et même le «touriste qui n'a pas vu», sans parler d'autres avatars du type «touriste», d'où la suspicion qu'on peut éprouver à l'égard du récit de voyage car l'écrivain qui voyage est d'abord un écrivain avant d'être un voyageur. Nathalie Solomon a raison de rappeler cette évidence illustrée par les écrivains romantiques. À partir d'exemples choisis dans des textes viatiques fort dissemblables (Chateaubriand, Lamartine, Custine, Stendhal, Hugo, Dumas, Nerval et Flaubert), sont esquissées les règles qui font du récit de voyage, considéré comme un objet narratif, une forme ou un modèle littéraire, ce qui implique l'étude du rapport à la réalité (la problématique réalité référentielle). C'est une réalité qui souvent n'existe qu'à partir d'autres représentations, littéraires, personnelles ou culturelles, et qui est réorganisée par la fiction. Hypothèse de départ: le voyage littéraire serait «avant tout imaginaire», quoique «issu d'une expérience vécue». D’où la nécessité de s'interroger sur la réalité du voyage.

2 Dans la première partie («Sur le genre», pp. 25-122), l'auteur s'intéresse aux variations des marques génériques et montre comment le narrateur, qui manie l'ironie, voire l'autodérision, s'emploie à détourner l'attention du lecteur. Tous les narrateurs jouent avec les codes du genre - d'ailleurs insuffisamment précisés -, les uns feignant d'adhérer aux modèles ou restant dans l'indécision formelle entre fiction et autobiographie quand, à partir de leurs carnets de notes, ils mettent en ordre le récit 
dans une relation rétrospective (le récit de voyage recomposé); les autres procédant à un «montage» selon une logique narrative variable qu'on peut suivre dans les «dérives» nervaliennes et la tendance systématique à la digression chez Stendhal. On remarquera dans la deuxième partie («Composition»), le chapitre VI: "Ordre ou désordre». $\mathrm{N}$. Solomon propose d'appréhender cette logique narrative à partir des affirmations du métadiscours qui visent et parviennent à intégrer «sans l'effacer, l'hétérogénéité du récit à un ensemble censé être cohérent» (p.138). Mais cette revendication de cohérence est plus virtuelle que réelle, notamment chez Gautier et Nerval, et même chez Lamartine dont la maîtrise affichée n'annule pas «une sensation de spontanéité, voire d'improvisation» (p. 146). Dans la troisième partie («Rêver le pays», pp. 161-200), les chapitres VII, «Hallucinations», et VIII, «Malgré le réel», abordent le vif du sujet, le pouvoir du fantasme. Même s'il arrive qu'il corresponde à ce que le voyageur a sous les yeux (à propos des femmes sur les terrasses de Malte, Lamartine déclare: «David vit ainsi Bethsabée»; dans les Cyclades, Nerval constate la mort de Pan; chez Hugo, devant la Mäuseturm, le fantasme se confond avec les paysage), le pouvoir du fantasme est tel que le voyageur confond le lieu tangible et le lieu rêvé, le passé et le présent, ou plutôt perçoit le passé dans le présent. Les fantasmes se nourrissant de la réalité, la fiction l'emporte. Quant à l'authenticité du voyage (chapitres IX et X, «Voyage et réalité», «Interprétation», pp. 203-238), ce n'est pas une question «sans doute oiseuse» et $\mathrm{N}$. Solomon a raison de ne pas s'en détourner. Ce qui importe, c'est le traitement de l'expérience, réelle ou imaginée. Un voyageur comme Gautier, mais c'est vrai aussi de Stendhal, subvertit les codes du genre, si bien qu'il arrive que le voyage ressemble plus à une aventure qu'à un exposé fiable: de témoin, le voyageur devient héros. Dans tous les cas de figure, c'est au lecteur de distinguer les plans de la réalité, en tenant compte des interventions de l'auteur, si singulières soient-elles. L'exemple des Promenades dans Rome est convaincant: l'intention pédagogique de Stendhal qui se veut le plus exact possible est évidente, mais la singularité de son regard est telle que «la page la plus descriptive devient absolument originale et personnelle» (p. 220). Dans d'autres cas, le narrateur s'octroie une marge de liberté par rapport au réel, par exemple par rapport à l'actualité immédiate ou à la modernité devant laquelle Chateaubriand gémit (les Turcs chez Périclès) et que Gautier dénonce avec virulence. Face au pays réel, c'est le désappointement pour certains, la «désillusion complète» (Flaubert), ce qui ne limite en rien le souci de dire la vérité du pays, quitte à la révéler sur le mode de l'ironie, jusqu'au trait grinçant de Flaubert. La partie fictionnelle des récits fait l'objet des trois derniers chapitres («Récits imaginaires», pp. 241-293). Dans les récits de voyage, la fiction, assimilée à l'obsession romanesque, est-elle centrale ou anecdotique? À lire Nerval ou Gautier, et tout autant Dumas, il est évident que «le narrateur n'est pas autre chose qu'un romancier»; sans doute est-ce vrai aussi, avec des modalités différentes dont il aurait fallu tenir compte, pour Stendhal qui, tout en peignant les Français du «King Philippe», se livre à ce qu'on pourrait appeler des digressions fictionnelles (récits enchâssés, récits amorcés ou esquissés, allusions à des récits supposés connus, etc.). Cette logique digressive fonctionne à plein dans ses récits de voyage, mais on la retrouve aussi bien chez Nerval, à un autre degré: le Voyage en Orient établit avec la fiction un rapport si déterminant et si complexe que s'abolit la frontière entre la relation véridique et la fiction. Dans ce récit de voyage, le narrateur compte plus que les lieux visités, aussi N. Solomon peut-elle dire, à propos du rapport de Nerval à la fiction, que «le monde est de la littérature». 
3 Au moment de conclure, et après avoir proposé des analyses convaincantes, N. Solomon craint que son lecteur n'ait pas les idées beaucoup plus claires sur ce qu'il advient de la réalité sous la plume des voyageurs romantiques. Qu'elle se rassure. Sans doute est-il difficile de démêler chez eux le vrai du faux, mais dans l'écriture romantique du voyage la recomposition compte plus que la représentation puisqu'elle permet de voir le monde dans toutes ses potentialités. Si le fantasme l'emporte, c'est heureux! 